\title{
Nanotechnologia łączenia metali z materiałami niemetalicznymi
}

\section{Nanotechnology of metal and non-metal joining}

\section{Streszczenie}

Rozwój elektroniki i metod symulacji wysokonapięciowych procesów wyładowań elektrycznych umożliwił opracowanie w Rosji nowej metody łączenia metali z niemetalami. Zaproponowano perspektywiczną metodę łączenia materiałów o specjalnych właściwościach fizykomechanicznych w obniżonej temperaturze i przy obniżonym ciśnieniu - zgrzewanie z wykorzystaniem przekładek metalicznych (folii).

Podczas sterowanego wyładowania wysokonapięciowego następuje szybkie odparowanie materiału przekładki. Powstałe wówczas pary metalu o dużej energii kinetycznej uderzają w powierzchnię materiałów łączonych, gdzie następuje krystalizacja. Na powierzchni niemetalu tworzy się cienka warstwa metalu, ściśle przylegająca do podłoża o identycznej sieci krystalograficznej jak niemetal. Uzyskana warstwa pośrednia umożliwia wykonanie trwałych połączeń. Istotnym elementem procesu jest znikome nagrzanie materiału podłoża.

W artykule przedstawiono wybrane aspekty krystalograficzne połączeń metali z materiałami niemetalicznymi, metoda metalizacji powierzchni parami metali w wyniku odparowania materiału folii po wyładowaniu elektrycznym.

\section{Abstract}

Development of electronic and also high-voltage disharge simulations enabled obtaining in Russia new method of metals and non-metals joining. The method is dedicated to materials with specific physical and mechanical properties in decreased temperature and pressure - welding with metal insrts.

In regulated high voltage electrical discharge material of insert is evaporated in short period of time. Vaporized metal with high kinetic energy are crashed into the joining materials surface, where the material crystallization process is observed. Thin layer of metal with the same crystal lattice as non-metal, which adhere to it with high strength, is produced on the surface of non-metal. High quality joints are achieved due to this metallic interlayer. Very low temperature of non-metal substrate is important aspect of the process.

Some of the crystallographic aspects of metal with non-metal joining in the process of surface metallization by metal evaporation in electric discharge is presented in this paper.

\section{Wstęp}

Rozwój i doskonalenie współczesnej elektroniki i budowy przyrządów stosowanych w lotnictwie i innych dziedzinach przemysłu nie byłby możliwy bez zastosowania nowych materiałów konstrukcyjnych, wytwarzonych na bazie ceramiki, szkła ceramicznego

Prof. dr hab. Gennadii Vladimirovich Koniushkov, doc. dr Aleksandr Nikolaevich Balakanin, inż. Vladimir Gennadevich Koniushkov - Państwowa Politechnika w Saratowie. (sital), kwarcu, ferrytów i innych materiałów niemetalicznych. Materiały te powstają na osnowie tlenków różnych pierwiastków i mają wyjątkowe właściwości fizykochemiczne.

Połączenia materiałów ceramicznych i materiałów ceramicznych z metalami znajdują zastosowanie w konstrukcji elementów systemów wysokoczęstotliwościowych, okien kontrolnych i falowodowych, ekranów i obudów przyrządów elektronowych i jarzeniowych (gas-discharge), fotokatodach w przyrządach noktowizyjnych, obudowach żyroskopów laserowych, akceleratorach, produkcji wyrobów jubilerskich itp.

Tradycyjne metody wykonywania takich połączeń - klejenie i lutowanie - nie zawsze zapewniają 


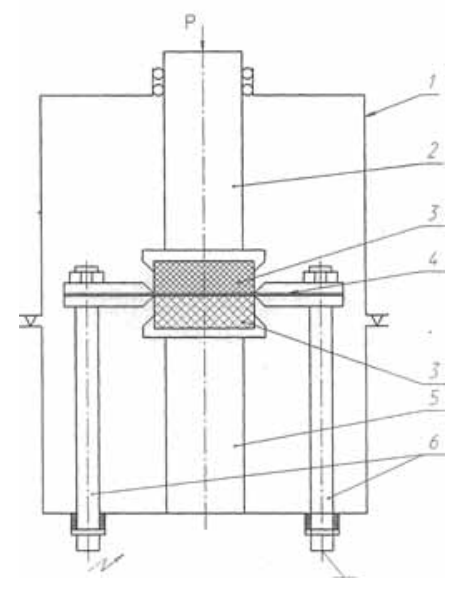

Rys. 1. Urządzenie do zgrzewania materiałów ceramicznych z wykorzystaniem folii metalicznej metodą wyładowania elektrycznego; 1 - komora próżniowa, 2 - ruchomy trzpień, 3 - elementy ceramiczne, 4 - folia metaliczna, 5 - stół roboczy, 6 - układ zasilania $(10 \div 25 \mathrm{kV})$

Fig. 1. The device for ceramic and metal with metal insert in electric discharge joining: 1 - vacuum chamber, 2 - moving mandrel, 3 - ceramic elements, 4 - metal insert, 5 - workplace, 6 - power input $(10 \div 25 \mathrm{kV})$

wysoką wytrzymałość, szczelność próżniową, odporność na temperaturę, kontakt cieplny i elektryczny, zachowanie właściwości podczas długotrwałego przechowywania. Natomiast metody spawania oparte na bardzo intensywnym wpływie ich parametrów na materiały łączone: zgrzewanie wybuchowe, zgrzewanie zgniotowe w próżni, spawanie impulsem magnetycznym, próżniowo-termiczna obróbka impulsem magnetycznym raczej nie nadają się do produkcji takich węzłów.

Najbardziej perspektywiczną metodą uzyskania połączeń metal-ceramika jest zgrzewanie dyfuzyjne w próżni, ale jego realizacja przy zastosowaniu tradycyjnych metod tej technologii łączenia $\left(T_{\mathrm{sp}}=(0,7 \div 0,8) T_{\text {top }}\right.$; $\left.P_{s p}=(0,8 \div 0,9) \sigma_{P_{3}}\right)$. Ponadto zastosowanie znanych już technologii dla wielu materiałów ceramicznych (ferrytów, sitali, piezoceramik) nie zawsze gwarantuje uzyskanie połączeń wysokiej jakości i zachowanie ich specjalnych właściwości.

Wydaje się, że najlepszą metodą łączenia tych materiałów sa odmiany zgrzewania dyfuzyjnego elementów w obniżonej temperaturze i ciśnieniu, w procesie metalizacji powierzchni odparowanym materiałem przekładek (folii) wskutek wyładowania elektrycznego (WWE) przeprowadzanego pomiędzy łączonymi powierzchniami (rys. 1).

Eksperymenty wykazały, że technika zgrzewania powoduje powstanie cienkiej metalicznej powłoki na powierzchniach łączonych materiałów. Trwałość jej przylegania do materiału ceramicznego ma decydujący wpływ na właściwości złącza oraz jest uzależniona od liczby atomów pierwszej warstwy kondensatu, tworzących wiązania chemiczne $z$ materiałem podstawowym - warstwa przejściowa ma nieznaczną grubość.
$\mathrm{Na}$ podstawie dostępnej literatury można stwierdzić, że procesy te nie zostały zbadane w sposób wystarczający. Publikacje dotyczą głównie przewodników liniowych (drutowych), a przewodniki płaskie praktycz-

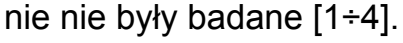

Przedmiotem publikacji jest przedstawienie zasad, modeli i nanotechnologii łączenia niemetali konstrukcyjnych z metalami i niemetalami przy zastosowaniu cienkich folii metalicznych metodą wyładowań elektrycznych przeprowadzanych w próżni.

\section{Analiza teoretycznych i eksperymentalnych wyników wyładowania elektrycznego}

Opis elektrycznego wybuchu przewodnika został wykonany wg schematu obwodu oscylacyjnego ze zmienną rezystancją, a model procesu wybuchu przekładki podczas spawania dielektryków ma postać równania różniczkowego, opisującego szeregowy obwód oscylacyjny ze zmienną rezystancją:

$$
\frac{\mathrm{d}^{2}}{\mathrm{dt}^{2}} \mathrm{~V}(\mathrm{t})+\frac{\mathrm{R}_{\mathrm{o}}+\mathrm{R}_{\mathrm{n}}(\mathrm{t})}{\mathrm{L}} \cdot \frac{\mathrm{d}}{\mathrm{dt}} \mathrm{V}(\mathrm{t})+\frac{\mathrm{l}}{\mathrm{L} \cdot \mathrm{C}} \cdot \mathrm{V}(\mathrm{t})=\mathrm{C}
$$

gdzie: $R_{n}(t)$ - empiryczna funkcja oporu przewodnika, $\left(R_{n}-\right.$ rezystancja zewnętrznego obwodu elektrycznego); $V(t)$ - napięcie w kondensatorze; $R_{o}$ - początkowa rezystancja przewodników; $C$ - pojemność kondensatorów, $L$ - indukcyjność rozładowania obwodu elektrycznego. a)

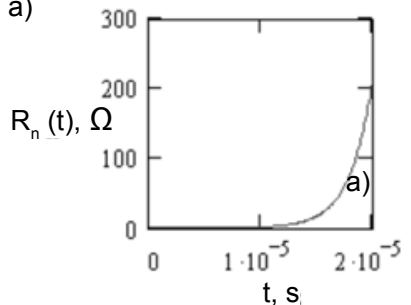

c)

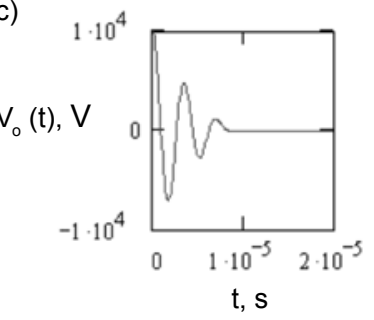

b)

I (t), A

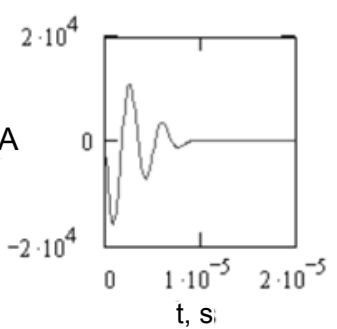

d)

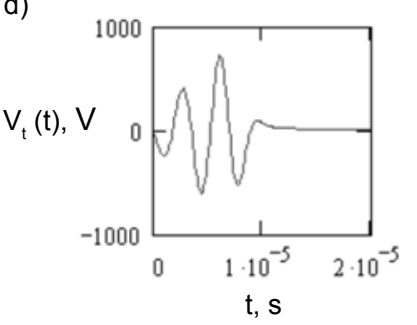

Rys. 2. Wykresy zależności od czasu rozładowania: a) rezystancji przewodnika, b) prądu rozładowania w obwodzie elektrycznym, c) napięcia baterii, d) napięcia w przewodniku, przy parametrach: $\mathrm{R}_{\mathrm{o}}=0,1 \Omega, \mathrm{L}=3 \times 10^{-7} \mathrm{GH}, \mathrm{C}=10^{-6} \mathrm{~F}, \mathrm{R}_{\mathrm{n}}=0,01 \Omega\left(\mathrm{W}_{\mathrm{n}}=13,198 \mathrm{~J}\right.$, $\left.W_{c}=50 \mathrm{~J}\right)$

Fig. 2. The function in discharge time of: a) conductor resistance, b) discharge current, c) battery voltage, d) conductor voltage, with parameters: $R_{0}=0,1 \Omega, L=3 \times 10^{-7} \mathrm{GH}, \mathrm{C}=10^{-6} \quad \mathrm{~F}, \mathrm{R}_{\mathrm{n}}=0,01 \Omega$ $\left(W_{n}=13,198 \mathrm{~J}, W_{c}=50 \mathrm{~J}\right)$ 


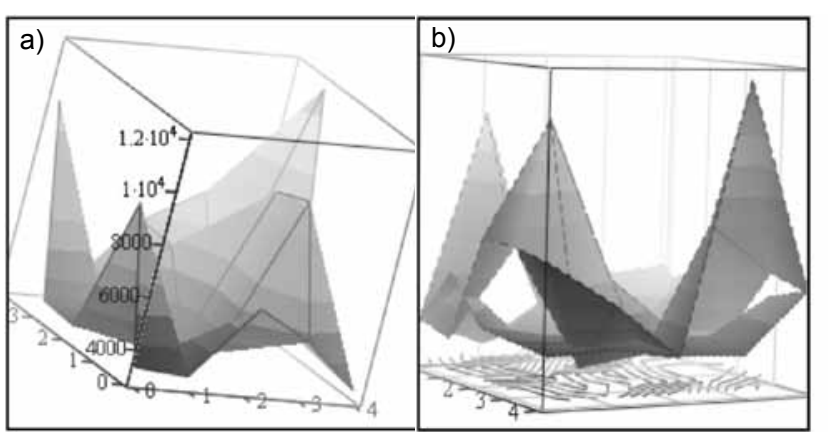

$T_{R g}\left(3,1 \cdot 1 \sigma^{-5}, 0.1,1000,1 \cdot 1 \sigma^{-6}\right) \quad T_{R_{g}}\left(3,1 \cdot 1 \sigma^{-5}, 0.1,10001 \cdot 1 \sigma^{7}\right) T_{R_{g}}\left(3.1 \cdot 1 \sigma^{-5}, 0.1,10003 \cdot 1 \sigma^{-7}\right)$ $T_{\mathrm{Rg}}\left(., 1 \cdot 10^{-5}, 0.1,10001 \cdot 10^{-6}\right)$

Rys. 3. Rozkład temperatury na powierzchni przewodnika dla trzech kolejnych momentów czasu

Fig. 3. The temperature decomposition on the surface of conductor in three time periods

Na rysunku 2 przedstawiono zależności rezystancji przewodnika, prądu rozładowania w obwodzie elektrycznym, napięcia na baterii kondensatora i na przewodniku od czasu. Wyznaczenie najlepszych parametrów obwodu elektrycznego dla wybuchu wykonywane jest $z$ uwzględnieniem rezystancji materiału folii.

W opracowanym modelu cyklicznego wyładowania elektrycznego uwzględniono ziarnistą budowę warstw metalicznych, a w szczególności niejednorodność rezystancji materiału. Rezystancja granic ziaren, faz drobnoziarnistych i innych niejednorodności jest znacznie większa niż rezystancja wewnątrz ziaren. W modelu płaskiego przewodnika tę niejednorodność uwzględniono przez wprowadzenie siatki o przypadkowym lub regularnym rozrzucie wartości nominalnych rezystancji.

Obliczenia modelu wykonano metodą macierzową z wykorzystaniem oprogramowania MathCAD na przygotowanym do tego celu stanowisku o dużej mocy obliczeniowej (ABM Athlon(tm) 64X2, procesor z podwójnym rdzeniem $4800+2,5 \mathrm{GHz}, 2 \mathrm{~Gb}$ RAM).

Wykonano 30 prób. Czas jednej próby z siatką $100 \times 100$ wynosił ok. 2 min, a łączny czas obliczeń ok. 60 min. Rozkłady temperatury dla trzech momentów czasowych na powierzchni przewodnika przedstawiono na rysunku 3. Zaobserwowano wyraźny wzrost temperatury na granicach ziaren.

Z modelu perkolacyjnego i wyników eksperymentalnych uzyskano opis fizyczny elektrycznego wyładowania przewodnika. Ze względu na znacznie większą rezystancję na granicach ziaren niż wewnątrz ziaren, topienie metalu zaczyna się od ich granic i rozprzestrzenia się w głąb, a ogólny udział stopionych ziaren nie przekracza 0,7 .

Mechanizmy oddziaływania materiałów przy łączeniu z zastosowaniem wybuchu elektrycznego materiału folii $w$ próżni zostały określone na podstawie badań krystalograficznych tworzenia połączeń, przeprowadzonych dla różnych materiałów w stanie stałym w stosunkowo niewysokich temperaturach.

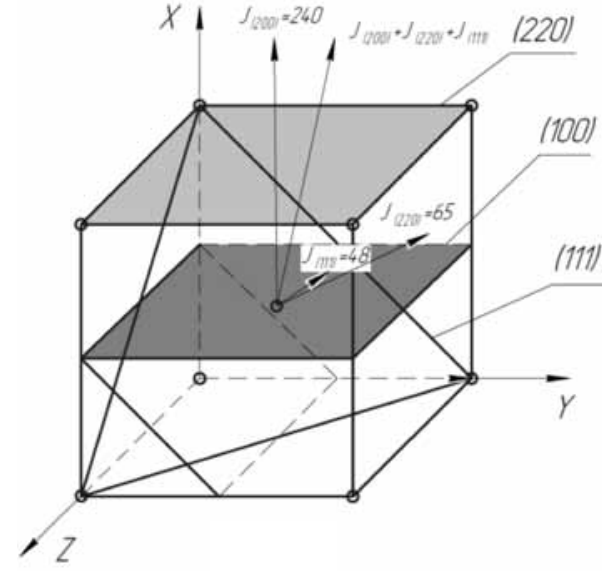

Rys. 4. Stan krystalograficzny materiału folii

Fig. 4. Crystalline state of insert material

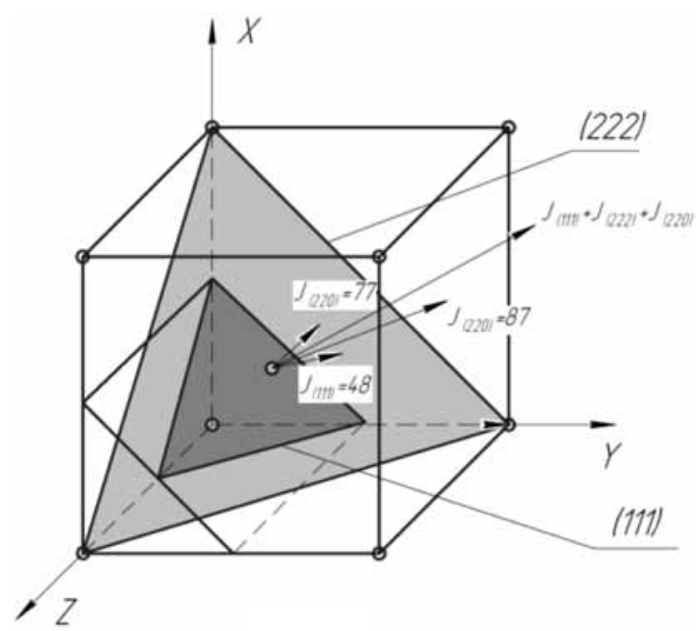

Rys. 5. Stan krystalograficzny warstw metalicznych uzyskanych w wyniku elektrycznego wybuchu folii w próżni

Fig. 5. Crystalline state of metallic layers produced in electrical discharge of insert in vacuum

Temperatura była na tyle mała, aby wpływ zjawisk heterodyfuzji i dyfuzji na zgrzewanych powierzchniach nie był znaczący, a uzyskane połączenia mogły być klasyfikowane jako połączenia adhezyjne.

Badania dyfraktogramów folii metalicznej wykonanej z materiału 47ND przedstawiono na rysunku 4, natomiast na rysunku 5 pokazano materiał tej folii po wykonaniu połączenia zgrzewanego z zastosowaniem elektrycznego wybuchu folii w próżni.

Folię na rysunkach opisano za pomocą wektorów określających orientację powierzchni krystalograficznych, tzn. materiał folii zorientowano powierzchnią (200), co jest równoznaczne z powierzchnią (100) do powierzchni walcowania. Uzyskana wskutek wybuchów elektrycznych w próżni powłoka na powierzchni szkła ceramicznego jest zorientowana powierzchnią (222), co jest równoznaczne z powierzchnią (111) do powierzchni podłoża. 
Z przedstawionych opisów wynika, że topienie i krystalizacja doprowadziły do pożądanej zmiany orientacji kierunków krystalograficznych $\mathrm{w}$ warstwie metalicznej. Przeprowadzone badania rentgenostrukturalne powierzchni warstwy niklu po zniszczeniu połączeń wzdłuż granic kontaktu wykazały istotne zmiany intensywności odbić od powierzchni $z$ niskimi indeksami Millera. Tablica relacji intensywności odbić powierzchni (111):(200):(220):(311) wynosi odpowiednio 100:50:32:32, a po połączeniu 100:394:124:106, co świadczy o tym, że przy krystalizacji ziarna $\mathrm{Ni}$ orientuja się ku podłożu w większości krawędziami kryształu podstawowej komórki. Można zakładać, że z punktu widzenia termodynamiki prowadzi to do uzyskania większej energii, ponieważ swobodna energia krawędzi kryształu niklu wynosi $1060 \mathrm{~mJ} / \mathrm{m}^{3}$, a powierzchni przestrzennej przekątnej (111) - $926 \mathrm{~mJ} / \mathrm{m}$.

Przy zastosowaniu metody łączenia wybuchowych wyładowań elektrycznych folii w próżni zapewnia to możliwość uzyskiwania wysokiej jakości połączeń metali i niemetali, a także niemetali z niemetalami (ceramika + ferryty, szkło ceramiczne + szkło kwarcowe, rubin + rubin i in.).

\section{Wnioski}

Na podstawie badań rozwiązano zadanie naukowe dotyczące opracowania podstaw nanotechnologii łączenia materiałów w wyniku wyładowań elektrycznych warstw metalicznych w próżni w obniżo- nych temperaturach i ciśnieniach zapewniających uzyskanie dobrej jakości połączeń metali, metali z materiałami niemetalicznymi i niemetali z niemetalami.

\section{Literatura}

[1] Koniushkov V.G., Model processov soedinenija dielektrikov sposobom vzryvajuscichsja provodnikov, A.Ja. Zorkin, O.Ju. Zhevalev, V.G. Koniushkov, Szybkokrzepnące materiały i powłoki, 7. Ogólnorosyjska Konferencja Naukowo-Techniczna z udziałem międzynarodowym. Zbiór prac - Moskwa, MATI RGTU im. K.E. Ciołkowskiego, 2008.

[2] Koniushkov V.G., Kristallograficeskie aspekty obrazovanija soedinenij raznorodnych materialov $v$ tverdoj faze, R.A. Musin, G.V. Koniushkov, Prace IV Międzynarodowej Konferencji Naukowo-Technicznej „Współczesne problemy budowy maszyn" - Tomsk, TGU, 2008
[3] Koniushkov V.G.: Perkoljacionnaja model elektriceskogo vzryva provodnikov v vakuume, V.G. Koniushkov, XVI Konferencja Naukowo-Techniczna $z$ udziałem zagranicznych specjalistów „Nauka i technika próżniowa” - Moskwa, MIEM 2009, s. 47-51.

[4] Koniushkov V.G., Nanotechnologii pri svarke cerez elektriceski vzryvaemye prosloi v vakuume, V.G. Koniushkov, Prace Międzynarodowej Konferencji Naukowo-Technicznej „Osiągnięcia współczesnej elektrotechnologii” - Saratow, Wyd. SGU 2009, s. 211-214.

Z języka rosyjskiego tłumaczył Andrei Bukharov

\section{W następnym numerze}

Wiodący temat numeru 2/2011: Metodyka opracowania i przykłady planów spawania

Jacek Słania

Plan spawania - omówienie zagadnienia

Jacek Słania, Jacek Skóra

Plan spawania wymiennika ciepła chłodzonego powietrzem

Jacek Słania, Dominik Wodecki

Plan spawania belki poprzecznej dźwigu

Jacek Słania

Plan spawania przy wykonywaniu napraw bieżących kotłów parowych, kotłów wodnych i stałych zbiorników ciśnieniowych

\section{Jacek Słania}

Plan spawania carg płaszcza pieca obrotowego

Michał Urzynicok, Jacek Słania

Analiza kosztów spawania przy wytwarzaniu kotłowych konstrukcji spawanych 